\section{Kidney \\ Blood Pressure Research}

Kidney Blood Press Res 2014;39:526-535

\title{
Up-Regulation of Intrarenal Renin- Agiotensin System Contributes to Renal Damage in High-Salt Induced Hypertension Rats
}

\author{
Haiyan Wu Yaoxian Liang Yimu Zheng Qiong Bai Zheng Zhuang \\ Lata A Danxia Zheng Yue Wang \\ Department of Nephrology, Peking University Third Hospital, Beijing 100191, China
}

\section{Key Words}

Angiotensinogen • Angiotensin II • High-salt diet • Hypertension • Intrarenal RAS

\begin{abstract}
Background/Aims: To investigate the change of intrarenal renin-agiotensin system (RAS) and its role in high-salt induced hypertension. Methods: Wistar rats were divided into normal-salt (NS), high-salt diet (HS) and high-salt diet with Losartan group $(\mathrm{HS}+\mathrm{L})$, for 6 weeks. Systolic blood pressure (SBP) was monitored. Blood and urine samples were collected every 2 weeks. Angiotensinogen (AGT) was measured by ELISA. AGT mRNA and protein were measured by real-time PCR and immunohistochemistry. Renin activity and angiotensin II (Ang II) were measured by radioimmunoassay. Results: HS versus NS group, SBP increased from $2^{\text {nd }}$ week $(P<0.05)$, urinary protein increased at $6^{\text {th }}$ week $(P<0.05)$. Although plasma renin, AGT and Ang II had no significant changes $(P>0.05)$, renal cortex renin, AGT, and Ang II increased significantly in $\mathrm{HS}(P<0.05)$. In $\mathrm{HS}+\mathrm{L}$, Losartan failed to reduce SBP $(P>0.05)$ but abolished the increase of proteinuria $(P<0.01)$, renal cortex renin, AGT, Ang II and urinary AGT reduced $(P<0.05)$ while plasma renin, AGT and Ang II enhanced $(P<0.05)$ when compared with HS. Urinary AGT was positively correlated with renal AGT $(r=0.592, P<0.01)$ and Ang II $(r=0.726, P$ $<0.01$ ). Conclusion: Inappropriate response of the renal RAS to a high salt diet may contribute to hypertension and renal damage, and urinary AGT could reflect intrarenal RAS activity.
\end{abstract}

Copyright $@ 2014$ S. Karger AG, Basel

\section{Introduction}

There is growing evidence that kidney has a complete functional intrarenal reninangiotensin system (RAS). Angiotensinogen (AGT) and Angiotensin converting enzyme (ACE) 


\section{Kidney Blood Pressure Research}

\begin{tabular}{l|l}
\hline Kidney Blood Press Res 2014;39:526-535 \\
\hline DOI: $10.1159 / 000368463$ & (c) 2014 S. Karger AG, Basel
\end{tabular}

Publisned ontine: November 29, 2014

Wu et al.: Intrarenal RAS in High-Salt Rats

are abundant in kidney and located in the proximal and distal tubules, collecting ducts, and renal endothelial cells. Renin secreted by juxtaglomerular apparatus cells can be delivered to renal interstitium. Angiotensin II (Ang II) in kidney is generated from locally produced and the sequestration from circulation. Angiotensin I delivered to the kidney can also be converted to Ang II, and the level of Ang II in the kidney is much higher than it in plasma. As the key component of RAS, AGT can regulate the Ang II level in kidneys [1, 2]. A large amount of investments suggest that the level of urinary AGT which is excreted from kidney is correlated with the augmentation of intrarenal AGT expression and Ang II content [3,4], and urinary AGT may serve as a new biomarker to reflect the activity of intrarenal RAS $[5,6]$.

In recent years, the interest in the pathophysiology of hypertension and target organ injury has changed to the role of local RAS in specific tissues, especially in kidney as the pivotal management of blood pressure and fluid and electrolyte balance [1, 2]. In traditional theory, the normal response to an increased salt intake is the suppression of circulation RAS. Ingert et al. found that the renin and Ang II levels changed in a manner inversely related to sodium content of the diet in both plasma and renal tissues [7]. However, in recent studies, such as in salt-sensitive hypertension in Dahl rats [8] and in spontaneous hypertension rats (SHRs) [9], researchers found that plasma renin activity and Ang II level decreased when given high-salt diet, but intrarenal AGT and Ang II level increased during the development of hypertension and renal damage, and the increase of intrarenal Ang II was associated with inappropriate augmentation of intrarenal AGT level [8-10]. In Ang II-infused hypertension, it was found that the proximal intratubular concentrations of ANG I and Ang II were much greater than their corresponding plasma concentrations, which suggested that the intrarenal RAS might play a critical role. Ang II up-regulated the formation of AGT as a positive feedback in contrast with the negative feedback with the circulation RAS, might indicate an independent regulation of intrarenal RAS [11]. Lara et al. found that in SD rats, HS could independently stimulate oxidative stress and inflammation but it also synergized with the inappropriate high level of Ang II to exacerbate hypertension and kidney injury [12]. A study examining the effects of dietary salt on intrarenal RAS in salt-sensitive and salt-resistant rat kidneys (SSR and SRR) found that high-salt diet lowered plasma renin activity but increased kidney Ang II-positive cells and AT1R in SSR but not in the SRR, which suggested that salt sensitivity in the SSR, was associated with up-regulation of the intrarenal RAS [13].

Excessive salt intake exerts severe detrimental effects on cardiovascular and renal structure and function in spontaneously hypertensive rats (SHRs) [10] and normotensive Wistar-Kyoto (WKY) rats [14]. Studies suggested that RAS was involved in the adverse effects of salt, since RAS blockade could prevent or ameliorate salt-induced cardiovascular and renal injury in SHRs [15]. However, the change of intrarenal RAS and its role in high-salt diet induced hypertension models is unclear. The present study was determined to examine the change of intrarenal RAS in high-salt induced hypertension Wistar rat models.

\section{Material and Methods}

\section{Animals}

Twenty seven male Wistar rats (Technical name: Vr:WI, bred by Wistar Institute in USA in 1907, and introduced by Vital River from Charles River Laboratories Inc in 2011)weighing 250 $\pm 20 \mathrm{~g}$ were used. The experimental protocol was approved by the Committee for animal Experiments of the Peking University Medical Department. Animals were housed in a temperature-controlled room with a $12 \mathrm{~h}$ light-dark cycle, and they were allowed one week to adjust after arrival and had free access to food and water during the entire study.

\section{Experimental design}

Rats were divided randomly into three groups and placed on a normal-salt diet (NS group, $0.3 \% \mathrm{NaCl}$ in chow; $\mathrm{n}=9$ ), a high-salt diet (HS group, $8 \% \mathrm{NaCl}$ in chow; $\mathrm{n}=9$ ) or a high-salt diet with Losartan (HS+L group, $8 \% \mathrm{NaCl}$ in chow and Losartan $20 \mathrm{mg} / \mathrm{kg}$ per day in gavages; $\mathrm{n}=9$ ) for 6 weeks. During the study, 


\section{Kidney Blood Pressure Research}

Wu et al.: Intrarenal RAS in High-Salt Rats

systolic blood pressure (SBP) was measured every 2 weeks in conscious rats by tail-cuff plethysmography (Softron biotechnology). Urine ( $24 \mathrm{~h}$ ) was collected every 2 weeks in metabolic cages with measurement of urinary volume and water intake. Urinary protein was determined in the clinical laboratory at Peking University Third Hospital. After 6 weeks, the rats were sacrificed, blood was collected by cannulation of the abdominal aorta, and kidneys were perfused in situ and immediately removed, quickly weighed. Left kidneys were snap-frozen in liquid nitrogen immediately and stored at $-80^{\circ} \mathrm{C}$, right kidneys were fixed in $4 \%$ paraformaldehyde.

Collection and extraction of blood, kidney, and urine samples

Blood was collected in prechilled anticoagulation tube containing a mixed inhibitor solution. After centrifugation at $4^{\circ} \mathrm{C}$ for $10 \mathrm{~min}$ at $3000 \mathrm{~g}$, plasma was separated and stored $-20^{\circ} \mathrm{C}$ until applied to measurements. Right kidneys were sectioned for measuring the expression of AGT by immunohistochemistry staining. Left renal cortex was dissected from inner medulla under stereomicroscopy and homogenated for tissue renin activity, Ang II and AGT measurements. Urine samples were obtained and centrifuged at $3000 \mathrm{~g}$ for $10 \mathrm{~min}$; supernatants were separated and stored at $-20^{\circ} \mathrm{C}$.

\section{Plasma renin activity and renal renin content}

Plasma was separated and assayed by a commercially available Plasma Renin Activity 125I RIA kit (The north biotechnology research institute, Beijing). 200mg of left kidneys were immersed in precold homogenization buffer (2.6 mM EDTA, $3.4 \mathrm{mM}$ hydroxyquinoline, $5 \mathrm{mM}$ ammonium acetate, $200 \mu \mathrm{M}$ PMSF, and $0.256 \mu \mathrm{M}$ dimercaprol), homogenized, and after centrifugation, supernatants were used to assess the renal renin content by Renin Activity 125I RIA kit. The procedure in brief, after rapid thawing, 500 $\mu \mathrm{l}$ plasmas or supernatants were adjusted to $\mathrm{pH} 6.0$ by adding a mixture containing citrate buffer and phenylmethylsulfonyl fluoride as angiotensinase inhibitor and incubated at $37^{\circ} \mathrm{C}$ and $4^{\circ} \mathrm{C}$ (blanks) for 90 min. After incubation, the RIA was performed. The concentration of Ang I was calculated by extrapolation of a standard curve with the lowest calibrator at $0.3 \mathrm{ng} / \mathrm{ml}$ of Ang I. The value of PRA was calculated with blank subtraction. The functional sensitivity of the assay is set at $0.2 \mathrm{ng} / \mathrm{ml}$ per h for values within the working range (from 0.2 to $50 \mathrm{ng} / \mathrm{ml}$ per h).

\section{Plasma, urine and renal Ang II}

The prestored samples: plasma, urine and supernatants of kidney tissue homogenization, were assayed by a commercially available ${ }^{125}$ I-radiolabled Ang II kit according to the manufacture's instruction (The North Biotechnology Research Institute, Beijing).

\section{Expression of kidney AGT mRNA}

According to the manufacturer's instructions, RNAs were extracted from renal cortex by TRIzol reagent (Invitrogen). The isolated RNA was converted into cDNA and quantitive RT-PCR was conducted by the Brilliant SYBR green QPCR system. The quantitive real-time RT-PCR data were normalized to GAPDH mRNA expression. Primer sequences were as follows: AGT, forward primer 5'-CTCGTCTTCCAGCACGACTT-3', reverse primer 5'- AGATTTGCCTCAGCACCCAA-3';GAPDH, forward primer 5'- CAGTGCCAGCCTCGTCTCAT3',reverse primer,5' - AAGGGCCATCCACAGTCTTC-3'.

\section{AGT level of plasma, kidney and urine}

Plasma and urinary concentrations of AGT were measured using an ELISA kit according to the manufacturer's instruction (Immuno-Biological Laboratories Co. Ltd, Tokyo, Japan), and urinary AGT excretion rates were calculated for the $24 \mathrm{~h}$ volume. Both the intact AGT and des-angiotensin1angiotensinogen were measured by the ELISA method.

To quantify the AGT protein in the kidney, renal cortex were immersed in precold homogenization buffer (2.6 mM EDTA, $3.4 \mathrm{mM}$ hydroxyquinoline, $5 \mathrm{mM}$ ammonium acetate, $200 \mu \mathrm{M}$ PMSF, and $0.256 \mu \mathrm{M}$ dimercaprol), homogenized, and after centrifugation, the supernatants were used to assess the renal AGT content by the rat AGT ELISA kit. Total protein concentrations in the supernatants were quantified using BioRad Protein Assay (Bio-Rad) and a Micro BCA Protein Assay Kit. Data from rat AGT ELISA were normalized by the protein concentration. 


\section{Kidney \\ Blood Pressure Research}

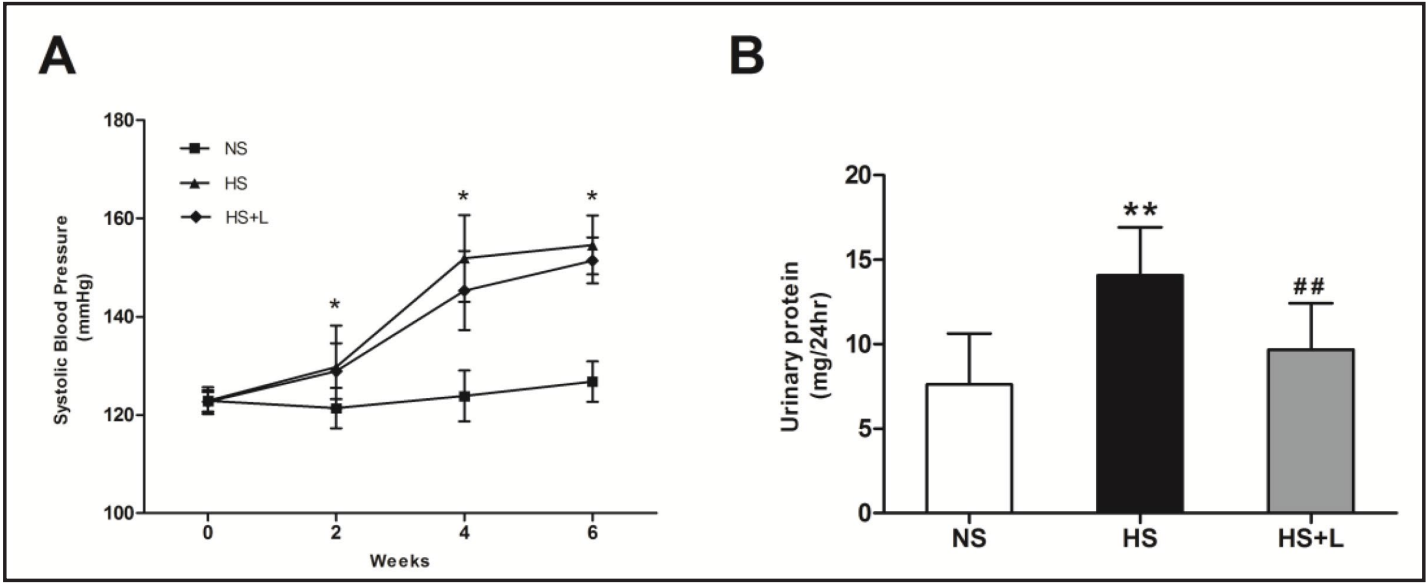

Fig. 1. The systolic blood pressure (A) and urinary protein (B). SBP was measured every 2 weeks in conscious rats by tail-cuff plethysmography, and the measurement was repeated 6 times for each rat every time. * $P<0.05$, ** $P<0.01$ vs. NS group. ${ }^{\#} P<0.05$, ${ }^{\# \# ~} P<0.01$ vs. HS group.

\section{Immunohistochemistry of renal AGT}

Formalin-fixed kidneys were dehydrated in gradated concentrations of alcohol, embedded in paraffin blocks, sectioned ( $3 \mathrm{um}$ ). Immunohistochemical analysis of AGT was performed with a rabbit polyclonal antimouse/rat AGT antibody (Immuno-Biological Laboratories Co. Ltd, Tokyo, Japan). For each rat, the cortical lesions in 20 consecutive microscopic fields were examined, and the intensities of AGT immunoreactivity were calculated and averaged using Image Pro Plus software (Media Cybernetics, Bethesda, MD).

\section{Statistical analysis}

Results were expressed as mean \pm SD. Data were analyzed by repeated-measures ANOVA with post hoc Newman-Keuls multiple comparison test within each group and by one-way ANOVA with post hoc NewmanKeels multiple comparison test between two groups. Correlations were evaluated by the least-square method. A value of $\mathrm{p}<0.05$ was considered statistically significant. Statistical analyses were performed using SPSS software, version 19.0 .

\section{Results}

Blood pressure and urinary protein excretion at $6^{\text {th }}$ week

At the beginning of the study, there was no significant difference in systolic blood pressure (SBP) among the three groups $(P>0.05)$. Compared with NS group, SBP of both HS group and HS+L group enhanced significantly from the 2 nd week and maintained to the end of the study $(P<0.05)$. There was no significant difference between SBP in HS group and HS+L group (Figure 1A).

Similarly, there was no significant difference in urinary protein excretion among three groups at the beginning of the study $(P>0.05)$. Compared with NS, urinary protein excretion increased significantly in HS rats at the 6th week $(P<0.01)$. Unlike SBP, at the end of study, urinary protein excretions decreased significantly in HS+L group versus HS group $(P<0.01)$ (Figure 1B).

The renin activity and Ang II levels in plasma and renal cortex at $6^{\text {th }}$ week

Plasma renin activity (PRA) and plasma Ang II level in HS group suggested no significant changes compared with NS group. However, the PRA $(P<0.05)$ and Ang II $(P<0.01)$ levels emerged a significant increase in HS+L group versus HS group (Figure 2). 


\section{Kidney Blood Pressure Research}

A

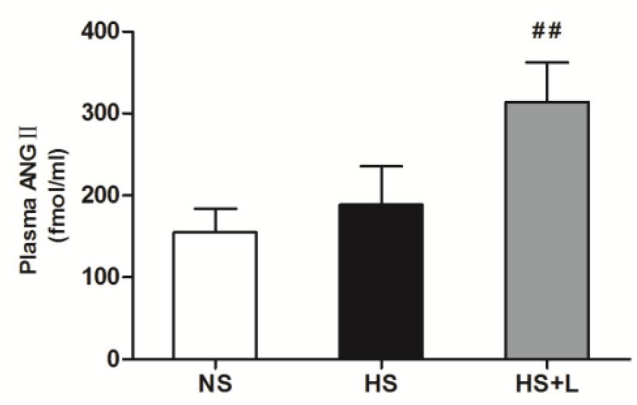

B

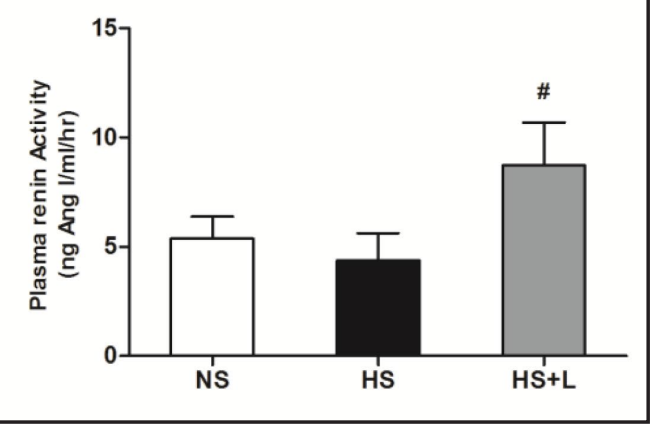

Fig. 2. The plasma renin activity and Ang II level. At $6^{\text {th }}$ week, radioimmunoactivity was used to examine PRA and Ang II, $\mathrm{n}=9$ for each group, every sample was examined twice. ${ }^{*} P<0.05$, ${ }^{* *} P<0.01$ vs. NS group. ${ }^{*}$ $P<0.05$, \#\# $P<0.01$ vs. HS group.

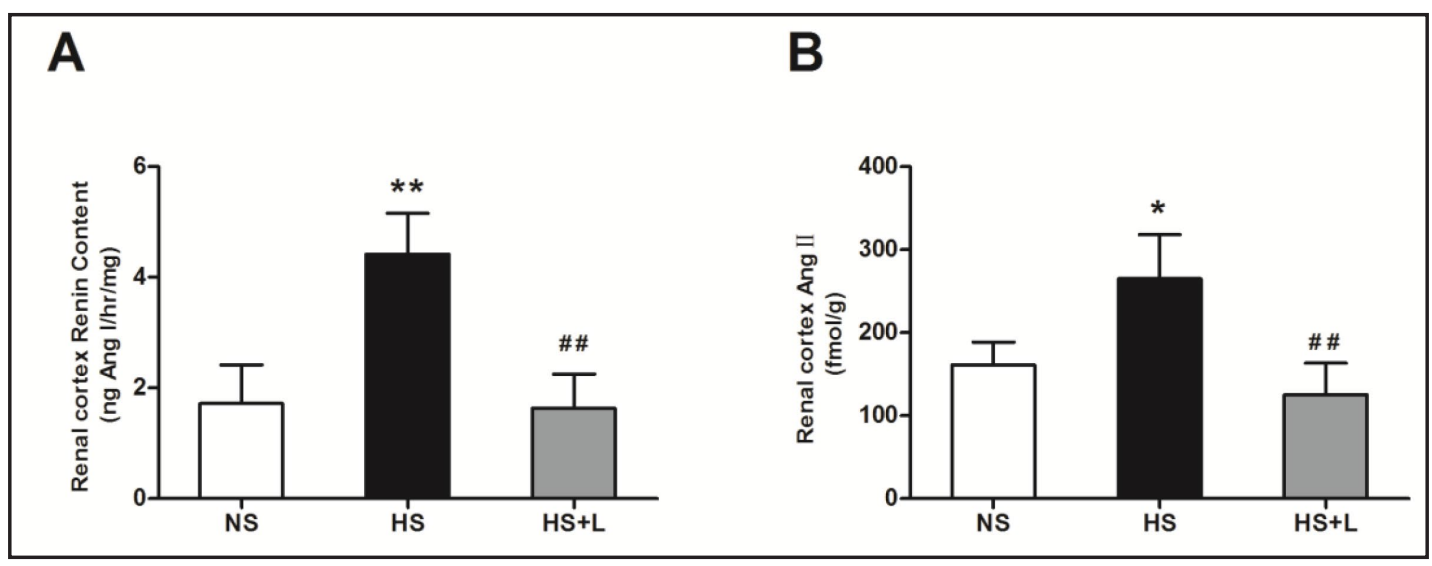

Fig. 3. The renal cortex renin activity and Ang II level. Renal cortex was homogenized and the supernatant was used to measure the renin activity and Ang II level by radioimmunoactivity, $\mathrm{n}=9$ for each group, every sample was examined twice. ${ }^{*} P<0.05$, ${ }^{* *} P<0.01$ vs. NS group. ${ }^{\#} P<0.05$, \#\# $P<0.01$ vs. HS group.

Renin activity and Ang II in renal cortex were significantly augmented in HS group compared with NS group $(P<0.05)$ and exhibited a significant decrease in HS+L group compared with HS group $(P<0.01)$ (Figure 3$)$.

The AGT level in plasma and kidney

Plasma AGT level suggested no significant changes neither in HS nor in HS+L group compared with NS group $(P>0.05)$ (Figure 4 A). However, in renal cortex, expression of AGT mRNA and protein, and AGT immunoreactivity exhibited a significant augmentation in HS group compared with NS group $(P<0.05)$, and suggested a significant decrease in HS+L group compared with HS group $(P<0.05)$ (Figure 4B, Figure 4C, Figure 4D, and Figure 5).

Excretion rates of AGT and Ang II in urine

Urinary excretion rates of AGT $(P<0.01)$ and Ang II $(P<0.05)$ in HS group were augmented significantly in HS group versus NS group, and there was a significant decrease in both urinary AGT $(P<0.01)$ and Ang II excretion rates $(P<0.01)$ in HS+L compared with HS (Figure 6). 


\section{Kidney Blood Pressure Research}

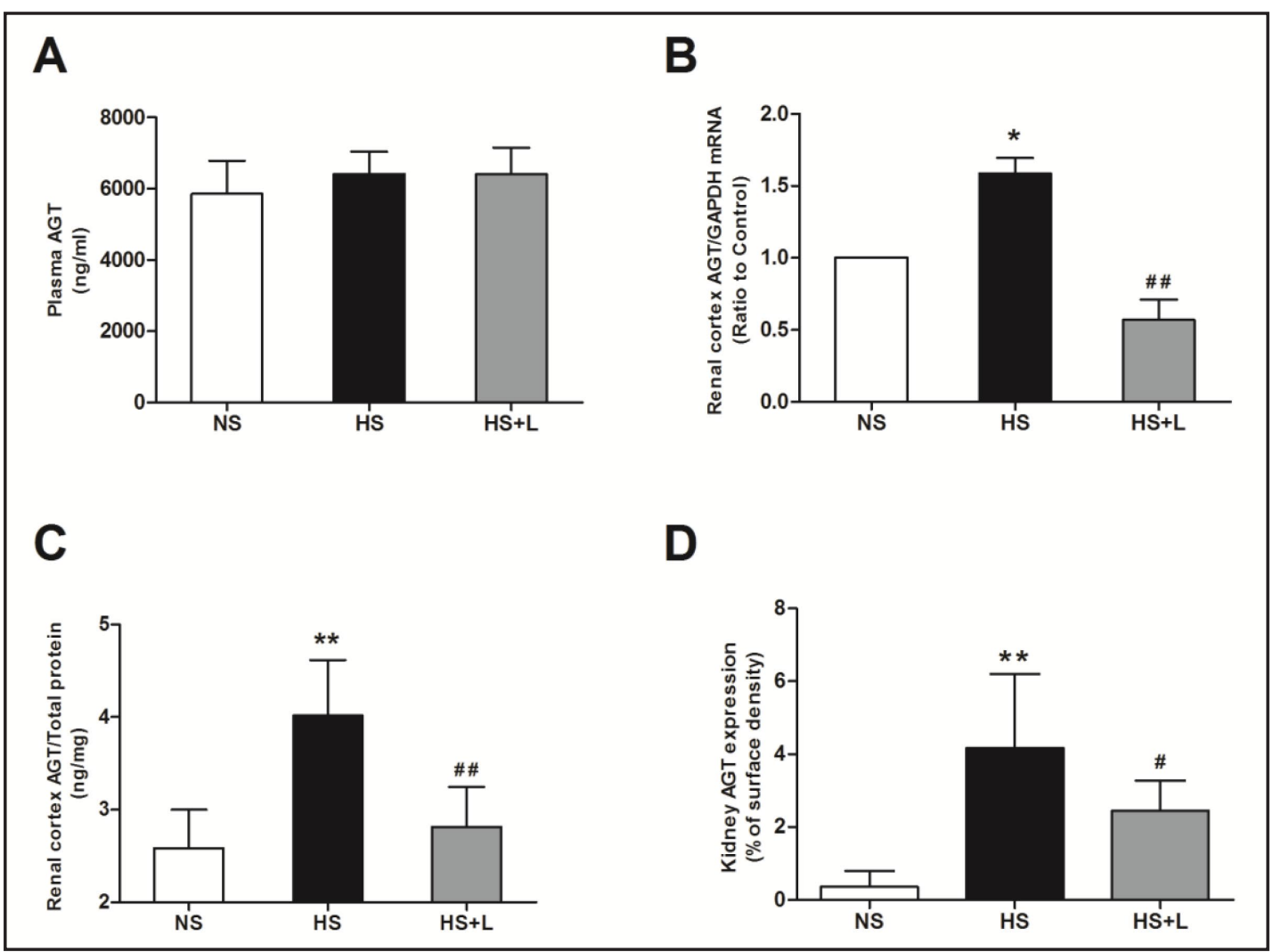

Fig. 4. The AGT level in plasma and kidney. The plasma and renal cortex AGT were measured by an ELISA kit (A and $C$ ). The mRNA expression in renal cortex was quantified by real-time PCR and adjusted by GAPDH mRNA (B). The extent of AGT expression was quantified in 20 different microscopic fields per tissue section per animal using an automatic image analysis of the area occupied by AGT-positive staining per microscopic fields (D). * $P<0.05$, ** $P<0.01$ vs. NS group. * $P<0.05$, \#\# $P<0.01$ vs. HS group.

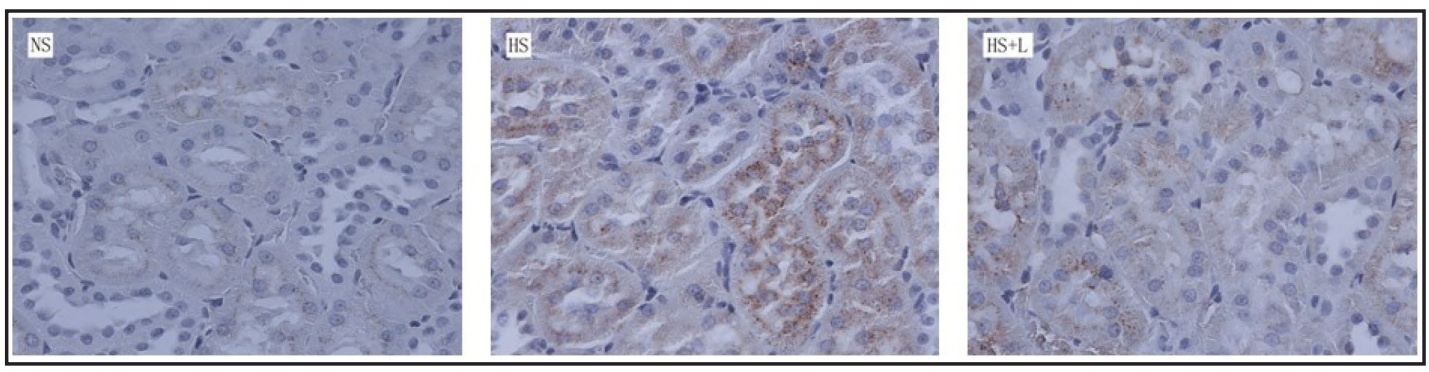

Fig. 5. Representative photomicrographs of AGT expression in kidneys visualized by immunochemistry staining in interstitial areas (x200). Proximal tubular AGT immunostaining was more intense in HS rats compared with that in the NS group, whereas in HS+L group, AGT immunostaining was less intense than that in HS group.

Correlation analysis of AGT and Ang II between urine and renal cortex

Urinary AGT excretion rates correlated positively with renal cortex AGT mRNA expression $(\mathrm{r}=0.912, P<0.01)$, AGT content $(\mathrm{r}=0.592, P<0.01)$ and AGT immunoactivity $(\mathrm{r}=0.758, P<0.01)$. Likewise, urinary Ang II excretion rates showed significant relationship with kidney Ang II content ( $\mathrm{r}=0.726, P<0.01)$. 


\section{Kidney \\ Blood Pressure \\ Research}

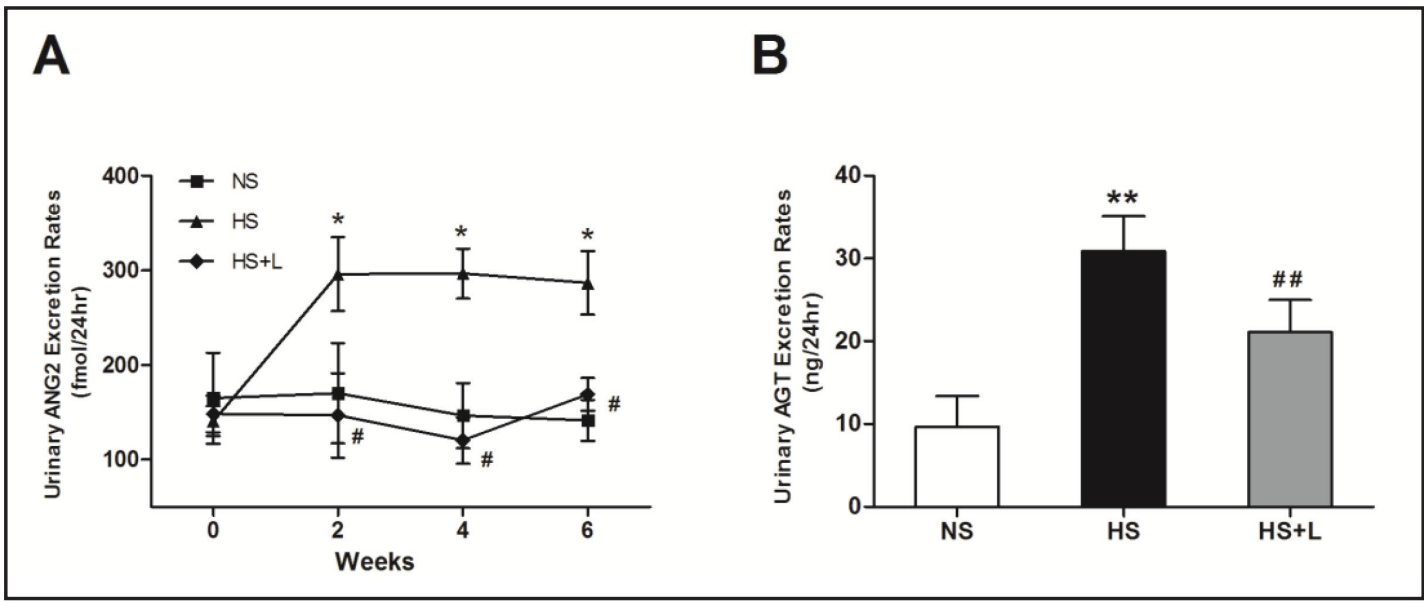

Fig. 6. The excretion rates of urinary Ang II and AGT. Radioimmunoactivity were used to examine Ang. Urinary AGT was measured by an ELISA kit, and adjusted by urine volume. $n=9$ for each group, every sample was examined twice. ${ }^{*} P<0.05$, ${ }^{* *} P<0.01$ vs. NS group. " $P<0.05$, \#\# $P<0.01$ vs. HS group.

\section{Discussion}

There currently is a great debate on whether RAS in kidney or in circulation contributes to the regulation of blood pressure and the development of hypertension. The classical dogma is that the circulation RAS rather than the intrarenal RAS plays an important role in the development of hypertension. It was reported that mice with the lack of vascular endothelial ACE may be normotensive or hypotensive [16] whereas mice with the lack of proximal tubular ACE may be normotensive [17]. However, recent studies strongly suggested that the proximal tubule ACE/ANGII/AT1R axis may mainly contribute to the development of hypertension. Over expression of AGT specifically in kidney could lead to chronic hypertension independently of the endocrine RAS in mice [18], and mice lacking intrarenal AGT synthesis developed less hypertensive damage in the kidney [19]. Coffman and Crowley's group studies confirmed that the kidney AT1R are absolutely required for the development of Ang II-dependent hypertension and cardiac hypertrophy [20]. Gurley et al. and Li et al. demonstrated that deletion of AT1R and its signaling in the proximal tubule alone was sufficient to significantly decrease basal blood pressure, despite the intact systemic AT1R expression and vascular responses [21, 22]. Jia L. and Zhuo et al. found that intrarenal transfer of AT1R alone exclusively in the proximal tubule was sufficient to increase SBP which was associated with two fold increases in phosphorylated MAP kinase ERK1/2, lysate and membrane NHE3 proteins in freshly isolated proximal tubules, and a decrease in 24h urinary sodium excretion[23].

The above studies were performed on gene transferred or gene deletion animals. In our studies, as intending to exclude other interferences and to find out the role of intrarenal RAS in wild-type normal animals, the forage containing $8 \% \mathrm{NaCl}$ was used to induce hypertension. We confirmed that as the blood pressure raised, the expression of RAS components in renal cortex increased correspondly while the plasma RAS components did not change significantly, indicating that intrarenal RAS may be more closely associated with high-salt induced hypertension. When Losartan was administrated to the high-salt diet rats, the up-regulation of RAS in renal cortex especially in proximal tubules were reduced even though the blood pressure was not lowed, indicating that intrarenal RAS was not the only pivotal mechanism for high-diet induced hypertension. The $20 \mathrm{mg} / \mathrm{kg} /$ day of Losartan is a usual dosage[24,25], but the other dosages such as $10 \mathrm{mg} / \mathrm{kg} /$ day[26], $100 \mathrm{mg} / 500 \mathrm{ml}$ in 


\section{Kidney \\ Blood Pressure Research}

\begin{tabular}{l|l}
\hline Kidney Blood Press Res 2014;39:526-535 \\
\hline DOI: $10.1159 / 000368463$ & (c) 2014 S. Karger AG, Basel
\end{tabular}

Publisned oninne: November 29, 2014 www.karger.com/kbr

Wu et al.: Intrarenal RAS in High-Salt Rats

drinking water[27], 30mg/kg/day[28] and so on, are also adopted by researchers. So, in the present study, the dosage of Losartan may be not sufficient to this type hypertension. Varagic et al. reported that AT1 receptor antagonism attenuates target organ effects of salt excess in SHRs without affecting blood pressure [29]. Previous studies have demonstrated that high-salt diet can lead to anomalous tubule-glomerular feedback which is pivotal to $\mathrm{NaCl}$ and fluid delivery to the distal nephron [30], and a study of Guild S J et al. has suggested that high-salt diet and elevated Ang II level could chronically increase renal sympathetic nerve activity [31]. Also, it is likely that the $8 \% \mathrm{NaCl}$ diet provides a marked overload of $\mathrm{NaCl}$ that may stimulate various cytokines, inflammatory factors and oxidative stress leading to inappropriate stimulation of intrarenal RAS. They all may contribute to the maintenance of hypertension in high-salt diet even in the presence of Losartan. Given that the activation status of intrarenal RAS varied independently upon or in controversy with plasma RAS, it may be well suggested that intrarenal RAS has its self-regulation which is independent of circulation RAS. There were also studies demonstrated that elevated Ang II not only induced hypertension but also elicited inflammatory and immunological response that contributed to interstitial fibrosis, glomerulosclerosis, albuminuria and finally, renal failure [32]. In the present study, proteinuria changed along with the expression of intrarenal RAS and was converse with the plasma renin activity or Ang II levels. This may suggest that inappropriate activation of intrarenal RAS may contribute directly to renal damage.

AGT is the only known substrate for renin, which is the rate-limiting enzyme of RAS. As the levels of AGT are close to Michaelis-Menten constant values for renin, and thus, upregulation of AGT in tissue leads to an increase in Ang II levels [33]. Over expression of AGT in renal proximal tubule in mouse, plasma AGT concentration was not altered, but urinary AGT was markedly increased compared with normal mouse [34]. In a glomerulosclerosis Munich-Wistar-Fromter rat model, researchers reported that the vast majority of urinary AGT originated from the tubules rather than glomerular filtration even when the glomerular filtration barrier was abnormal [35]. The present study suggested that urinary AGT and Ang II were closely related with renal AGT and Ang II levels which were consistent with the previous studies, and thus, it was concluded that urinary AGT could reflect the intrarenal RAS even in this animal model.

\section{Conclusion}

Our data demonstrated that high-salt may induce hypertension and renal damage by up-regulation of intrarenal RAS, blockage of AT1R decreased the proteinuria even though the blood pressure was not lowered, and urinary AGT could reflect the status of intrarenal RAS.

\section{Disclosure Statement}

All the authors declared no competing interests.

\section{Acknowledgements}

The study group consists of the following persons: WU Haiyan, LIANG Yaoxian, ZHENG Yimu, BAI Qiong, ZHUANG Zheng, A Lata, ZHENG Danxia, WANG Yue from Department of Nephrology, Peking University Third Hospital. This study was supported by grants from National Nature Science Foundation of China (no. 81070213) to WANG Yue. 


\section{Kidney \\ Blood Pressure Research}

\begin{tabular}{l|l}
\hline Kidney Blood Press Res 2014;39:526-535 \\
\hline DOI: 10.1159/000368463 & $\begin{array}{l}\text { (c) 2014 S. Karger AG, Basel } \\
\text { www.karger.com/kbr }\end{array}$ \\
\hline Publisned onlne: November 29, 2014 &
\end{tabular}

Wu et al.: Intrarenal RAS in High-Salt Rats

\section{References}

1 Kobori H, Nangaku M, Navar LG, Nishiyama A: The intrarenal renin-angiotensin system: from physiology to the pathobiology of hypertension and kidney disease. Pharmacol Rev 2007;59:251-287.

-2 Bader M: Tissue renin-angiotensin-aldosterone systems: targets for pharmacological therapy. Annu Rev Pharmacol Toxicol 2010;50:439-465.

- 3 Kobori H, Urushihara M: Augmented intrarenal and urinary angiotensinogen in hypertension and chronic kidney disease. Pflugers Arch 2013;465:3-12.

4 Urushihara M, Kobori H: Angiotensinogen expression is enhanced in the progression of glomerular disease. Int J Clin Med 2011;2:378-387.

-5 Mills KT, Kobori H, Hamm LL, Alper AB, Khan IE, Rahman M, Navar LG, Liu Y, Browne GM, Batuman V, He J, Chen J: Increased urinary excretion of angiotensinogen is associated with risk of chronic kidney disease. Nephrol Dial Transplant 2012;27:3176-3181.

-6 Urushihara M, Kondo S, Kagami S, Kobori H: Urinary angiotensinogen accurately reflects intrarenal reninangiotensin system activity. Am J Nephrol 2010;31:318-325.

7 Ingert C, Grima M, Coquard C, Barthelmebs M, Imbs JL: Effects of dietary salt changes on renal reninangiotensin system in rats. Am J Physiol Renal Physiol 2002;283:F995-F1002.

-8 Kobori H, Nishiyama A, Abe Y, Navar LG: Enhancement of intrarenal angiotensinogen in dahl salt-sensitive rats on high salt diet. Hypertension 2003;41:592-597.

-9 Kobori H, Ozawa Y, Suzaki Y, Nishiyama A: Enhanced intrarenal angiotensinogen contributes to early renal injury in spontaneously hypertensive rats. J Am Soc Nephrol 2005;16:2073-2080.

10 Susic D, Frohlich ED, Kobori H, Shao W, Seth D, Navar LG: Salt-induced renal injury in SHRs is mediated by AT1 receptor activation. J Hypertens 2011;29:716-723.

11 Navar LG, Kobori H, Prieto MC, Gonzalez-Villalobos RA: Intratubular renin-angiotensin system in hypertension. Hypertension 2011;57:355-362.

-12 Lara LS, McCormack M, Semprum-Prieto LC, Shenouda S, Majid DS, Kobori H, Navar LG, Prieto MC: AT1 receptor-mediated augmentation of angiotensinogen, oxidative stress, and inflammation in ang II-salt hypertension. Am J Physiol Renal Physiol 2012;302:F85-F94.

13 Chandramohan G, Bai Y, Norris K, Rodriguez-Iturbe B, Vaziri ND: Effects of dietary salt on intrarenal angiotensin system, NAD(P)H oxidase, COX-2, MCP-1 and PAI-1 expressions and NF-kappaB activity in saltsensitive and -resistant rat kidneys. Am J Nephrol 2008;28:158-167.

14 Frohlich ED, Chien Y, Sesoko S, Pegram BL: Relationship between dietary sodium intake, hemodynamics, and cardiac mass in shr and wky rats. Am J Physiol 1993;264:R30-R34.

15 Varagic J, Frohlich ED, Susic D, Ahn J, Matavelli L, Lopez B, Diez J: AT1 receptor antagonism attenuates target organ effects of salt excess in shrs without affecting pressure. Am J Physiol Heart Circ Physiol 2008;294:H853-H858.

16 Cole J, Quach DL, Sundaram K, Corvol P, Capecchi MR, Bernstein KE: Mice lacking endothelial angiotensinconverting enzyme have a normal blood pressure. Circ Res 2002;90:87-92.

-17 Kessler SP, Hashimoto S, Senanayake PS, Gaughan C, Sen GC, Schnermann J: Nephron function in transgenic mice with selective vascular or tubular expression of angiotensin-converting enzyme. J Am Soc Nephrol 2005;16:3535-3542.

18 Davisson RL, Ding Y, Stec DE, Catterall JF, Sigmund CD: Novel mechanism of hypertension revealed by cellspecific targeting of human angiotensinogen in transgenic mice. Physiol Genomics 1999;1:3-9.

19 Kang N, Walther T, Tian XL, Bohlender J, Fukamizu A, Ganten D, Bader M: Reduced hypertension-induced end-organ damage in mice lacking cardiac and renal angiotensinogen synthesis. J Mol Med (Berl) 2002;80:359-366.

-20 Crowley SD, Gurley SB, Herrera MJ, Ruiz P, Griffiths R, Kumar AP, Kim HS, Smithies O, Le TH, Coffman TM: Angiotensin II causes hypertension and cardiac hypertrophy through its receptors in the kidney. Proc Natl Acad Sci U S A 2006;103:17985-17990.

21 Gurley SB, Riquier-Brison AD, Schnermann J, Sparks MA, Allen AM, Haase VH, Snouwaert JN, Le TH, McDonough AA, Koller BH, Coffman TM: AT1A angiotensin receptors in the renal proximal tubule regulate blood pressure. Cell Metab 2011;13:469-475. 


\section{Kidney \\ Blood Pressure Research}

-22 Li H, Weatherford ET, Davis DR, Keen HL, Grobe JL, Daugherty A, Cassis LA, Allen AM, Sigmund CD: Renal proximal tubule angiotensin AT1A receptors regulate blood pressure. Am J Physiol Regul Integr Comp Physiol 2011;301:R1067-R1077.

-23 Li XC, Zhuo JL: Proximal tubule-dominant transfer of AT(1A) receptors induces blood pressure responses to intracellular angiotensin II in AT(1A) receptor-deficient mice. Am J Physiol Regul Integr Comp Physiol 2013;304:R588-R598.

-24 Refaat R, Salama M, Abdel ME, El SA, Gowayed M: Evaluation of the effect of losartan and methotrexate combined therapy in adjuvant-induced arthritis in rats. Eur J Pharmacol 2013;698:421-428.

25 Manni ME, Bigagli E, Lodovici M, Zazzeri M, Raimondi L: The protective effect of losartan in the nephropathy of the diabetic rat includes the control of monoamine oxidase type a activity. Pharmacol Res 2012;65:465-471.

26 Dal-Ros S, Oswald-Mammosser M, Pestrikova T, Schott C, Boehm N, Bronner C, Chataigneau T, Geny B, Schini-Kerth VB: Losartan prevents portal hypertension-induced, redox-mediated endothelial dysfunction in the mesenteric artery in rats. Gastroenterology 2010;138:1574-1584.

-27 Jian DY, Chao YW, Ting CH, Huang SW, Chang CF, Juan CC, Chen JY: Losartan ameliorates renal injury, hypertension, and adipocytokine imbalance in 5/6 nephrectomized rats. Eur J Pharmacol 2013;709:85-92.

28 Yang D, Zhang M, Huang X, Fang F, Chen B, Wang S, Cai J, Shi X, Qu J, Geng YJ: Protection of retinal vasculature by losartan against apoptosis and vasculopathy in rats with spontaneous hypertension. J Hypertens 2010;28:510-519.

-29 Varagic J, Frohlich ED, Susic D, Ahn J, Matavelli L, Lopez B, Diez J: AT1 receptor antagonism attenuates target organ effects of salt excess in SHRs without affecting pressure. Am J Physiol Heart Circ Physiol 2008;294:H853-H858.

-30 Singh P, Thomson SC: Salt sensitivity of tubuloglomerular feedback in the early remnant kidney. Am J Physiol Renal Physiol 2014;306:F172-180.

-31 Guild SJ, McBryde FD, Malpas SC, Barrett CJ: High dietary salt and angiotensin II chronically increase renal sympathetic nerve activity: a direct telemetric study. Hypertension 2012;59:614-620.

32 Muller DN, Shagdarsuren E, Park JK, Dechend R, Mervaala E, Hampich F, Fiebeler A, Ju X, Finckenberg P, Theuer J, Viedt C, Kreuzer J, Heidecke H, Haller H, Zenke M, Luft FC: Immunosuppressive treatment protects against angiotensin II-induced renal damage. Am J Pathol 2002;161:1679-1693.

33 Kobori H, Urushihara M: Augmented intrarenal and urinary angiotensinogen in hypertension and chronic kidney disease. Pflugers Arch 2013;465:3-12.

-34 Ying J, Stuart D, Hillas E, Gociman BR, Ramkumar N, Lalouel JM, Kohan DE: Overexpression of mouse angiotensinogen in renal proximal tubule causes salt-sensitive hypertension in mice. Am J Hypertens 2012;25:684-689.

-35 Nakano D, Kobori H, Burford JL, Gevorgyan H, Seidel S, Hitomi H, Nishiyama A, Peti-Peterdi J: Multiphoton imaging of the glomerular permeability of angiotensinogen. J Am Soc Nephrol 2012;23:1847-1856. 